\title{
USING WEBGIS AND CLOUD TOOLS TO PROMOTE CULTURAL HERITAGE DISSEMINATION: THE HISTORIC UP PROJECT
}

\author{
A. Tommasi ${ }^{\mathrm{a}}$, R. Cefalo ${ }^{\mathrm{a}}$, F. Zardini ${ }^{\mathrm{b}}$, M. Nicolaucig ${ }^{\mathrm{a}}$ \\ ${ }^{a}$ GeoSNaV Laboratory, Department of Engineering and Architecture, University of Trieste, Italy - agostino.tommasi@dia.units.it, \\ cefalo@geosnav.com,nicolaucig@geosnav.com \\ ${ }^{b}$ Historic Consultant, Trieste, Italy - francesco.zardini@live.it
}

KEY WORDS: GIS, WebGIS, WWI, Education, Tour Builder, Cloud

\begin{abstract}
:
On the occasion of the First World War centennial, GeoSNav Lab (Geodesy and Satellite Navigation Laboratory), Department of Engineering and Architecture, University of Trieste, Italy, in coooperation with Radici\&Futuro Association, Trieste, Italy, carried out an educational Project named "Historic Up" involving a group of students from "F. Petrarca" High School of Trieste, Italy.

The main goal of the project is to make available to students of Middle and High Schools a set of historical and cultural contents in a simple and immediate way, through the production of a virtual and interactive tour following the event that caused the burst of the First World War: the assassination of Franz Ferdinand and his wife Sofia in Sarajevo occurred on June 28, 1914.

A set of Google Apps was used, including Google Earth, Maps, Tour Builder, Street View, Gmail, Drive, and Docs. The Authors instructed the students about software and team-working and supported them along the research. After being checked, all the historical and geographic data have been uploaded on a Google Tour Builder to create a sequence of historical checkpoints. Each checkpoint has texts, pictures and videos that connect the tour-users to 1914. Moreover, GeoSNaV Lab researchers produced a KML (Keyhole Markup Language) file, formed by several polylines and points, representing the itinerary of the funeral procession that has been superimposed on ad-hoc georeferenced historical maps. This tour, freely available online, starts with the arrival of the royals, on June $28^{\text {th }} 1914$, and follows the couple along the events, from the assassination to the burial in Arstetten (Austria), including their passages through Trieste (Italy), Ljubljana (Slovenia), Graz and Wien (Austria).
\end{abstract}

\section{INTRODUCTION}

\subsection{Young people and First World War memory}

Thanks to the Centennial, the historical memory of First World War has considerably grown in these last years. Every nation that experienced the conflict is dedicating lots of projects and celebrations to the conservation and evaluation of the events that characterized one of the most brutal and dramatic wars ever fought.

\subsection{Civil value of WW1 memory}

Reflecting and working on the memory of the conflict can be a strong and incisive education to social and human values for new generations. However, young people (11 to 18 years old) often still consider history (including the history of WW1) as a boring discipline, far from contemporary events and ordinary life. This idea is widespread and the standard schooling often cannot remedy to it.

Conscious of the problem, the new historical projects have to face this situation by showing human experience between the dates of time chronology, that is, man faced with macro-events. Focusing on human condition, on the effects of the conflict on nations and mankind and comparing differences and similarities between today's reality and the war period, young people reach a growth in awareness. Hence, historical knowledge becomes part of a civil and responsible identity, built on past suffering and its causes awareness.

Today, this conscious and mature identity is more important than ever, since young people live an international reality that is still characterized by wars, fight for rights, reflections on dialogue and respect values.
Moreover, this kind of projects, based also on team working and cooperation, organization and problem solving, have a strong value as an introduction to future professional experiences.

\subsection{Cultural dissemination, young people and new technologies}

The difficulty of reaching young people with historical dissemination can find a solution in the use of new technologies. Indeed, new generations are used to interact directly and constantly with lots of realities thanks to new technologies and socials.

Projects about historical memories must consider this point as one of the fundaments of the idea. Students involved must be considered as responsible creators of culture and active witnesses of history towards their peers. Young people must have the possibility to face directly the sources of the events, learning how to understand them and translate them into items of culture and consciousness.

This is the reason why new technologies, web resources, apps, socials, must have a role into historical and cultural projects.

These resources are connections between young people's daily life and historical themes; furthermore, they enforce contests dissemination and enjoyment even for people who are usually uninterested. Moreover, students involved in a project can apply their skills in a new way, discovering software and the web as precious, professional and practical items. Finally, young people increase their sense of responsibility towards society and its values.

Knowledge of the dramatic story of the "lost generation" of 1914-18 may contribute to the new generation's ability to face the future. 


\subsection{Franz Ferdinand's last journey}

\section{THE HISTORIC UP PROJECT}

\subsection{The project goal}

On the occasion of the First World War centenary the Radici\&Futuro Association, Trieste, Italy, in partnership with four Middle and High-Schools from Italy and Croatia, has promoted a project named "The Great War in the sky, on earth and in the sea" with the aim of expanding the knowledge on WWI historical facts and promoting reflections by comparing them with the current geographical and historical situation.

One of the included activities was the educational Project named "Historic Up" involving a group of students from the " $F$. Petrarca" High School of Trieste, Italy and carried out by researchers belonging to GeoSNav Lab (Geodesy and Satellite Navigation Laboratory), Department of Engineering and Architecture, University of Trieste, Italy.

The main target of the Historic Up Project is to make available to Middle and High Schools students a set of historical and cultural contents in a simple and immediate way. Using Google Tour Builder, a virtual and interactive tour has been produced, following the journey of Franz Ferdinand and wife's bodies in the summer of 1914, from Sarajevo (Bosnia and Herzegovina) to Arstetten (Austria), through Trieste (Italy), Ljubljana (Slovenia) and Vienna (Austria).

The reconstruction of Franz Ferdinand's last journey is an opportunity for the young generation to compare present and past history and geography for educational purposes. Virtually travelling together the royal bodies it is possible to get a picture of the last moments of peace in the Austro-Hungarian Empire, just before the coming of the storm. A certain resignation for the coming events can be seen in retrospect along the route in clergy, army, aristocracy and population mourning. This is visible through the pictures and videos uploaded by the authors and linked to the POI (Point of Interest) along the itinerary.

\subsection{Tools used for the Historic Up Project}

To ensure advanced real-time cooperation between the teamwork members, a full set of Google Apps was used, including Google Earth, Maps, Tour Builder, Street View, Gmail, Drive, and Docs. The Authors instructed the students on how to use the software, structured workflow and hierarchy inside the working groups, and supported them during the sources research phase.

In particular, the Google Drive cloud platform was used to store and share between the participants all the collected data. Inside the Google Drive environment, text editing operations have been carried out with the Google Docs application.

The webGIS part of the educational project was based on the Tour Builder ${ }^{1}$ platform. Tour Builder is an online tour creator (currently in beta version) based on Google Earth engine that enables the user to create a personal multimedia tour. Every tour checkpoint can host one text description and up to 25 photos and videos, each with its own caption and title. In addition, it is also possible to specify the exact date on which the historical fact happened. Tour Builder is accessible from the most common web browsers, making it easy to place the locations and add all the textual and multimedia informations. It is possible to share the tour by making it public and sending a direct link. A Tour Builder downside is its lack of mobile devices support; however, it's possible to download the tour as a KML (Keyhole Markup Language) file that can be viewed on the mobile Google Earth app.

By default Tour Builder connects the itinerary placemarks with straight lines; however in this project those simple lines have been replaced with a custom and more detailed track, representing the precise route travelled (See 2.4 "Precise route reconstruction" for more details).

It is interesting to note that Tour Builder, as reported on his website, was originally created to "give veterans a way to record all the places that military service has taken them, and preserve their stories and memories as a legacy for their families". Therefore, is even more fitting to use it to cover an event related to the WWI.

\subsection{Work organization}

The project involved 12 High School students and various collaborators from GeoSNaV Lab, Radici\&Futuro, and Liceo Petrarca teaching staff. The students have been divided into 3 groups, each devoted to a section of the journey:

\begin{tabular}{|c|c|c|c|}
\hline \multirow[b]{2}{*}{ Group name } & \multicolumn{3}{|c|}{ Tour section } \\
\hline & $\begin{array}{c}\text { Starting } \\
\text { point }\end{array}$ & $\begin{array}{c}\text { Ending } \\
\text { point }\end{array}$ & $\begin{array}{l}\text { Means of } \\
\text { transport }\end{array}$ \\
\hline Group 1 & Sarajevo & Metkovic & Car/Train \\
\hline Group 2 & Metkovic & Trieste & Ship \\
\hline Group 3 & Trieste & Artstetten & Train/Carriage \\
\hline
\end{tabular}

Table 1. Group organization

The working groups, searching through web pages and public archives and catalogues, have collected a great amount of historical information, photos and (when existing) videos concerning Franz Ferdinand's assassination and the transport of his corpse to the burial site. All the owners of the data intellectual property (text, photos and videos) have been contacted by the students in order to obtain the permission to publish the material for educational purposes. All the collected data and the original documents produced by the students have been hosted on a structured Google Drive folder system. A network Administrator from GeoSNav Lab regulated the participant's access permits for the various folder and subfolders according to their task and group assignments.

Three young members of the Radici\&Futuro association were assigned as supervisors to each working group with the task to check spatial accuracy, historical validity and publishing rights. Prior to the implementation on the Tour Builder platform, an historic consultant reviewed all the information and the multimedia files for a final quality check.

A synthetic scheme of work distribution and hierarchy structure is shown in Figure 1.

$1 \mathrm{https}$ //tourbuilder.withgoogle.com 


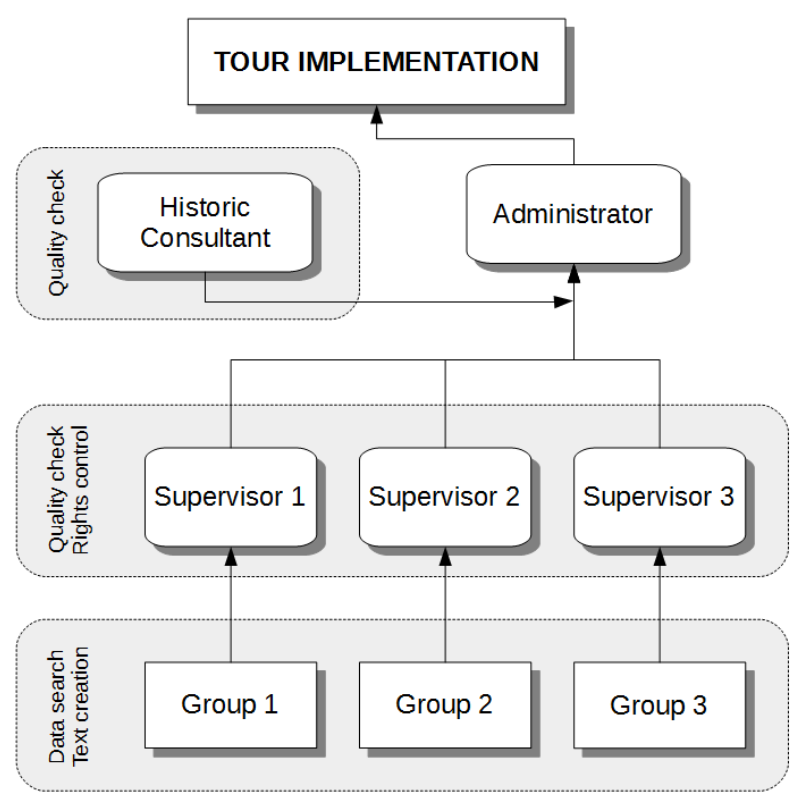

Figure 1. Hierarchy structure of the work groups

\subsection{Precise route reconstruction}

Rather than using the simple connecting lines offered by default by the Tour Builder platform, the Authors created and imported a KML file representing the precise itinerary of the funeral procession. In order to reconstruct the exact route travelled by the royal bodies, the members of GeoSNav Lab compared the analysed historical maps and documents with the current territory state. The procession itinerary reconstruction was complex because it involved various means of transportation, including cars, horse carriages, yachts, battleships (the Viribus Unitis) and trains.

\begin{tabular}{|lll|}
\hline Sheet & Title & Year \\
\hline $31-46$ & Triest & 1909 \\
$32-46$ & Laibach & 1893 \\
$32-47$ & Klagenfurt & 1894 \\
$33-46$ & Cilli & - \\
$33-47$ & Graz & 1893 \\
$33-48$ & St. Pölten & - \\
$34-48$ & Wien, Sorpon & - \\
$35-43$ & Mostar & 1895 \\
$35-44$ & Travnik & 1896 \\
$36-44$ & Sarajevo & 1914 \\
\hline
\end{tabular}

Table 2. List of the georeferenced Austro-Hungarian maps used for the Historic Up Project

The tour starts with the arrival by train of the Austro-Hungarian royals, on 28 June 1914 in Sarajevo, and follows their journey through the town until the fatal shooting. The first difficulty was to identify the location of the train station of Archduke's arrival. Various reports of that day (Lyon, 2015) showed that Franz Ferdinand firstly visited the Filipovic barracks on the west side of the town, were today the Sarajevo University campus is located. This means that they arrived on the nearly situated local Bahnhof (train station), that no longer exists.

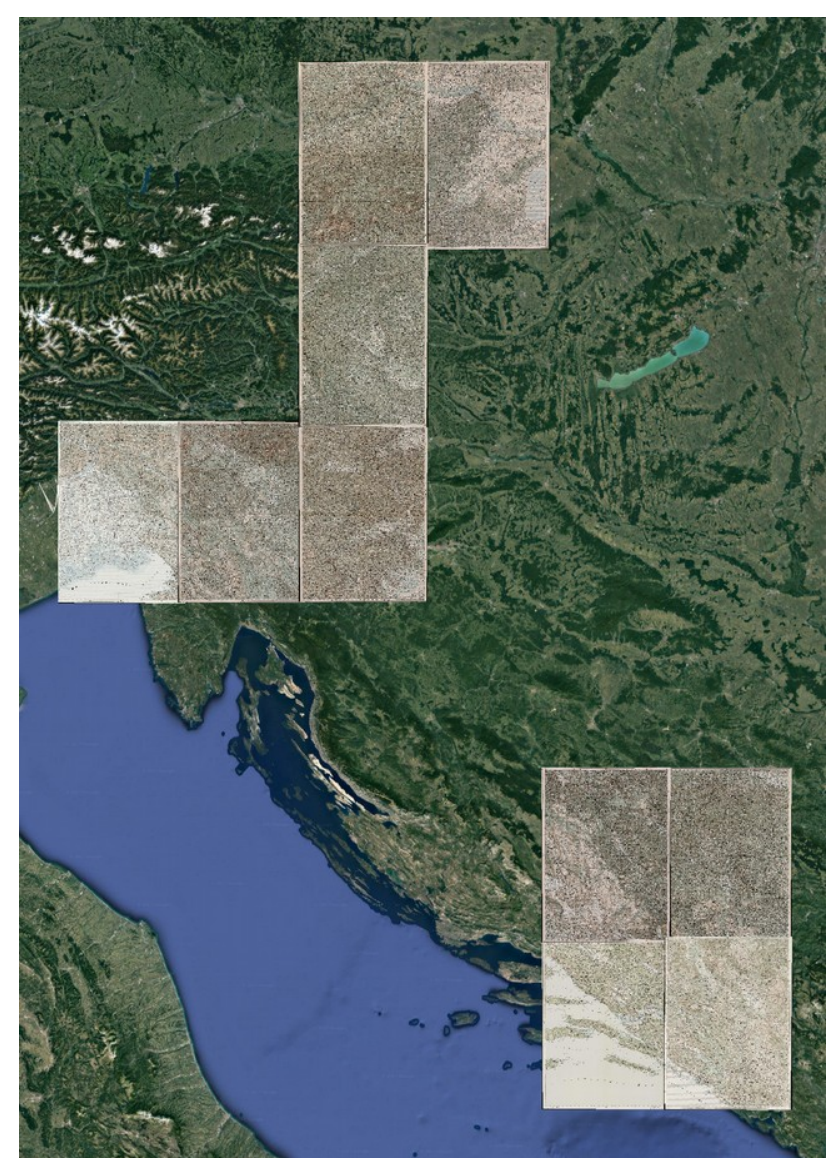

Figure 2. Overlay of the georeferenced historical maps on Google Maps satellite images (C2017 TerraMetrics)

After the visit to the Filipovic barracks, the Archduke and his wife started their parade through the city streets. The cars advanced slowly to allow the imperial heirs to admire some of the newly build Austro-Hungarian constructions.

The parade briefly stopped in front of the new Central Post Office building, still visible nowadays, where director Präsident Gaberl handed a telegram to Sofia from her children. A few hundred meters ahead, after the Austro-Hungarian Bank building, the Serbian Nedeljko Čabrinović threw a grenade at the convoy, missing his target. One passenger of another convoy car was injured, as well as several bystanders.

Following the failed attack, the procession headed at high speed toward the Town Hall. Here, despite the previous events, the visit continued as scheduled inside the Hall. At 10:45 in the morning the parade departed from the Town Hall in the direction of the Lateiner bridge, along the Miljacka river bank. According to the official program, the convoy had to turn right to Franz Jospeh Gasse (now Zelenih beretki) but Franz Ferdinand decided to continue along Quai Appel (now Obala Kulina bana) to visit the wounded at the military hospital. Since the driver didn't know the change of plan, the car had to stop and shift into reverse. Taking advantage of that moment, the Serbian Gavrilo Princip fired two gunshots, mortally wounding both the imperial heirs.

The car rapidly headed to the Governor Palace (Konak), on the other side of the Milijacka river, but there was clearly nothing to do as both Franz Ferdinand and Sofia were already deceased. 
The day after the assassination the funeral procession began along the road to the Bistrik railway station, were a special train had been prepared for their return journey.

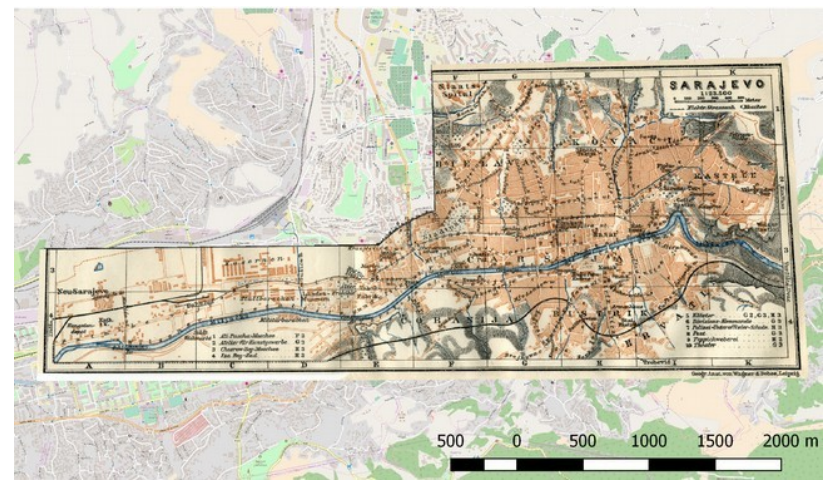

Figure 3. Historical map of Sarajevo city

The Authors reconstructed the railway section of the tour from Sarajevo Bistrik station to Metkovic using the 1929 AustroHungarian maps and analysing modern digital cartography and satellite images. The Authors imported the historical maps as raster layers in Quantum GIS; here, using the Georeferencer tool, the maps have been geo-referenced in the WGS84/World Mercator Reference System (CRS code 3395).

A map of Sarajevo city dated 1929, scale 1:23.500, has been used to identify the first part of this railway track, from the Bistrik railway station (still existing, but non-operating) to the main railway line. The analysis of the old cartography revealed that the ancient railway followed the actual Put Mladih Muslimana road and that the old railroad switch was located in the Dolac Malta district, near the actual Veterinary Faculty.

The next railway part of the journey, from Sarajevo to Mostar, was the most difficult to retrieve on modern digital cartography, as a great part of it was destroyed during the conflicts subsequent to 1914: World War I, World War II and the Yugoslav Wars. Also, some parts of the original line were flooded by the creation of a number of hydroelectric dams along the Luka and Narenta rivers. With the help of the georefenced old historic cartography it was possible to reconstruct the exact railway line travelled in June 1914 by the funeral train. Fig. 4 shows a comparison of the polyline track representing the actual railway line (red) and the second polyline extracted from 1914 cartography (orange) used in the tour (orange) near Konijc.

From Metkovic, the tour follows the naval procession that took the bodies to Trieste (Italy), first by yacht along the Narenta river and then, off the Dalmatian coast, on the Viribus Unitis battleship. The naval route track that starts from the river mouth is based on the historical indication of the harbors touched by the ship procession: first Spalato (Split), then Pula/Pola and finally Trieste. The arrival and funeral procession in Trieste are well documented; even some video footage is available. After the disembarkation, the bodies were transferred to carriages and transported to the Central Railway Station. A large number of people attended the funeral procession across the streets of Trieste. This part of the multimedia tour is the one covered in bigger detail, and gave the High School students an opportunity to interact with the history of their own town.

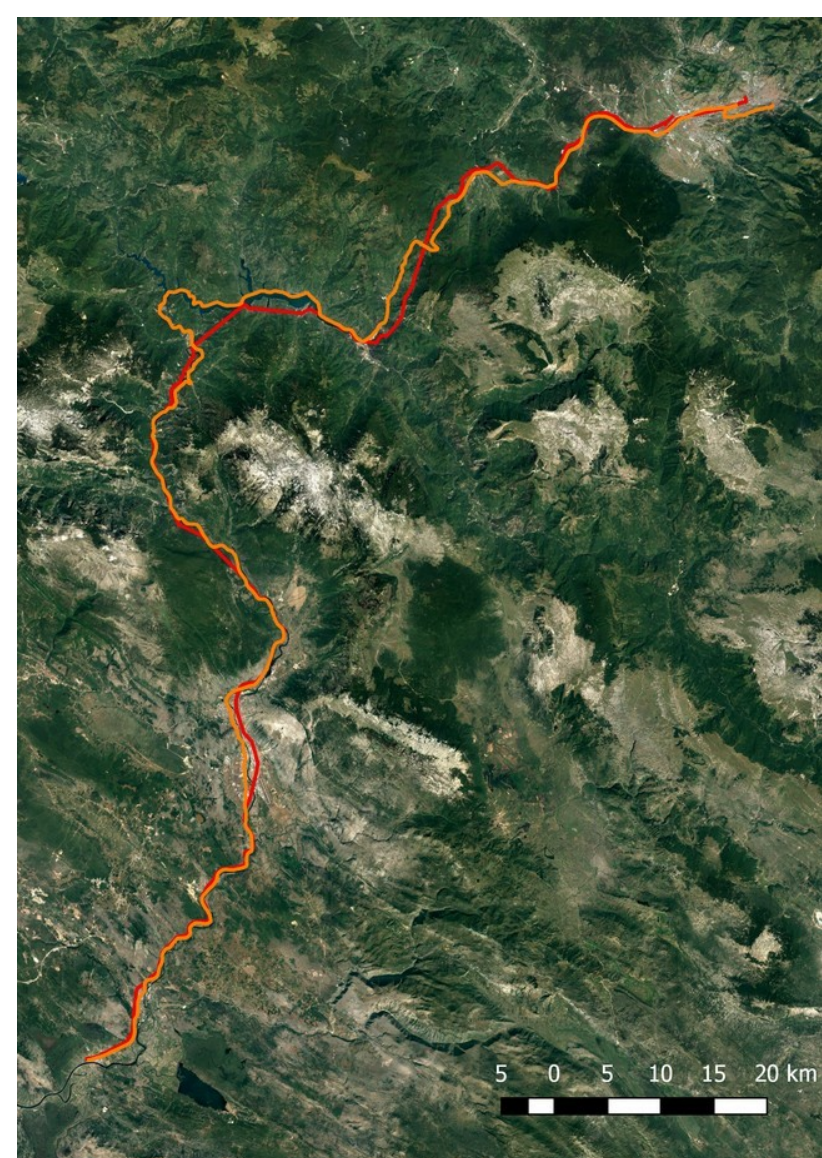

Figure 4. Different railway tracks from Sarajevo to Metkovic (Satellite images: Google Maps (C2017 TerraMetrics)

Starting from Trieste, a special train with the embalmed bodies headed toward Wien. This part of the tour follows the actual railway path, as it had no major changes during the last century. As emerged from historical documents, the procession passed through St. Peter in Krain (Pivka), Laibach (Ljubljana), Steinbrück (Zidani Most), Marburg an der Drau (Maribor), Graz and, finally, Wien.

From the Hauptabhnhof (Central Station) the procession travelled along Prinz Eugen-Straße and Kärntner Straße to reach the St. Stephen's Cathedral, where on the following day the funeral was held. In the evening, the remains of the emperial heirs were transferred to the Westbahnhof (West Station) where another special train transported them to Pöchlarn. From the Pöchlarn railway station, on the following morning, there started the last funeral procession that ended in the Artstetten Castle, where a last private burial ceremony was held.

\subsection{Tour implementation}

The GeoSNav Lab team, using all the data collected by the students and the georeferenced data obtained from GIS analysis and cartography interpretation, created a public available tour on the Tour Builder platform, named "Historic Up". A total of 36 placemarks have been located and linked with all the textual and multimedia data (over 70 photos and 2 videos) collected by the students and verified by the supervisors and the historic consultant. The straight connecting lines between the placemarks have been replaced with a KML vector file representing the 1914 exact route. 


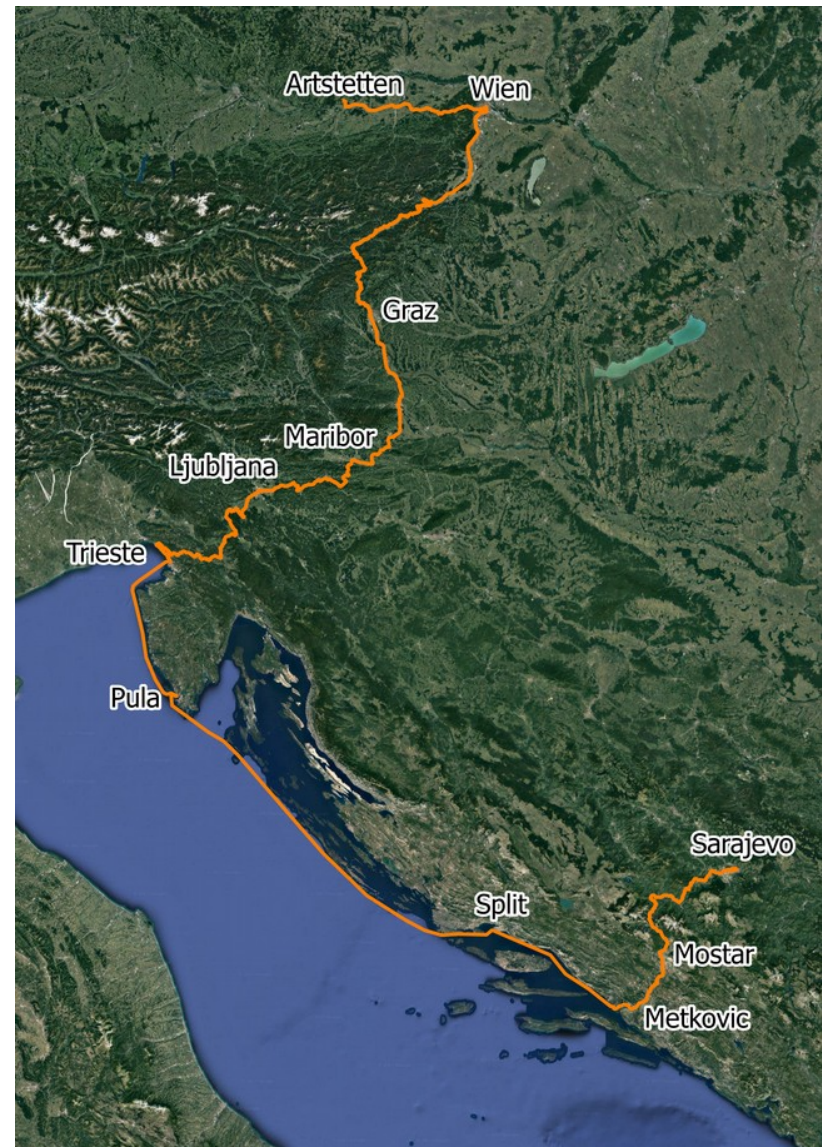

Figure 5. The reconstructed route

This interactive tour is freely available online on the Tour Builder platform (direct link: https://tourbuilder.withgoogle.com/tour/ahJzfmd3ZWItdG91 cm J1aWxkZXJyEQsSBFRvdXIYgIDA9qezswkM) and as a free downloadable KML file, which can be imported in Google Earth on PCs and mobile platforms and viewed as a virtual tour.

\section{CONCLUSIONS}

On June 281914 two gunshots changed the face of Europe and the entire world history. In Sarajevo, a Serbian /student killed the Austro-Hungarian Empire hereditary couple; as a result, one month later, WWI started. It was the greatest conflict ever seen before, with over 17 million deaths and 20 million wounded. In the present times, one hundred years later, it's possible to bring back to life the events that brought to the conflict step by step, like a live coverage from the past.

A group of High School students from Italy, supervised by GeoSNav Lab, reconstructed the journey of the bodies of the imperial heirs from their arrival in Sarajevo to their final burial in Artstetten. Using the Tour Builder platform, all the data collected by the students and verified by the team work have been inserted in a multimedia and georeferenced webGIS tour, freely available online.

In conclusion, one of the most salient historic moments of the last century's history - the assassination of Archduke Franz Ferdinand of Austria and his wife - has become an opportunity to stimulate and disseminate cultural heritage among the younger generations using free Web GIS platforms and socials.

\section{REFERENCES}

Agosto E., Ardissone P., Rinaudo F. (2007). GIS And WebGIS, Commercial and Open Source Platforms: General Rules for Cultural Heritage Documentation. In: International Archives Of The Photogrammetry, Remote Sensing And Spatial Information Sciences, vol. XXXVI-5/C53, pp. 625-630. - ISSN 1682-1750 http://porto.polito.it/2373419/ since: September 2010 Publisher: ISRPS.

Barrile V., Bilotta G., Medurri G. M. Un WebGis per i percorsi archeologico-culturali. In: Atti 17a Conferenza Nazionale ASITA - Riva del Garda 5-7 novembre 2013.

Bucciol, E., 2014. Space Data from Earth Sciences. Luglio editore, Trieste.

Harder C. 1998, Serving Maps on the Internet, ESRI Press, U.S.

Hickin B.W., Maguire D.J., Strachan A. 1991, Introduction to GIS: The Arc/INFO Method, Midlands Regional Research Laboratory, University of Leicester.

Lyon J., 2015. Serbia and the Balkan Front, 1914: The Outbreak of the Great War. Bloomsbury Academic, Graz.

Marshall J. 2000, Developing Internet-Based GIS Applications, in Proceedings of the Twentieth Annual ESRI User Conference, ESRI, Redlands, California.

Moltedo L., Picco R., Salonia P. 2000, La presenza delle Tecnologie dell'Informazione nella ricerca sui Beni Culturali: risultati di una indagine, «Archeologia e Calcolatori», 11, 301310 .

Negri A. 2002, Cultural Heritage: GIS solution for sharing knowledge over the WEB, in Atti del Primo Convegno della Sezione Italiana di Eurographics (Politecnico di Milano 2002), CD-ROM. del costruito storico, «Archeologia e Calcolatori», $11,219-240$.

Plini P., Di Franco S., Salvatori R., 2017. Geography of WWI sites along the Italian front by means of GIS tools. New Advanced GNSS and 3D Spatial Techniques, Springer International Publishing.

Salonia P. 2003, Strumenti informatici innovativi di ausilio alla conservazione del patrimonio storico-architettonico: problemi di organizzazione, diffusione e gestione dati, in M. Rossi, P. Salonia (eds.), Comunicazione multimediale per i Beni Culturali, Milano, Addison Wesley, 25-52.

Salonia P., Negri A. 1996, Strumenti e metodologie per la conoscenza del patrimonio edilizio storico: un sistema informativo.In: Atti del I International Congress on Science and Technology for the Safeguard of Cultural Heritage in the Mediterranean Basin (Catania, Siracusa 1995), Palermo, Luxugraph, 921-927.

Salonia P., Negri A. 2001, Dissemination of heterogeneous informations in the recovery of historical buildings: ARKISNET.In Atti del II International Congress on Science and Technology for the Safeguard of Cultural Heritage in the Mediterranean Basin (Alcalá de Henares 2001), CD-ROM. 
Salonia P., Negri A. 2003, Historical buildings and their decay: Data recording, analysing and transferring in an ITC environment. In: Atti dell'International Workshop Vision Tecniques for Digital Architectural and Archaeological Archives (Ancona 2003), Ancona, Università Politecnica delle Marche, 302-306.

Sipos A. 2011. Cadastral Maps in Central Europe - Aims and possibilities of archival cooperation, Poznań, 06. June 2011Budapest City Archives. http://documents.icarus.eu/documents/2012/04/cadastral-maps-work-grouppresentation-poznan-06-06-2011.pdf

Todero, F., 2014. Una violenta bufera. Trieste 1914. IRSLM, Trieste. 